\title{
MÉTODO RUSH:
}

\section{GERENCIAMENTO ÁGIL DE ITERAÇÕES PARA PROJETOS DE INOVAÇÃO}

Luís Gonzaga Trabasso ${ }^{1}$ Roberto Philippi Füllgraf ${ }^{2}$

\section{RESUMO}

Envolto no contexto do gerenciamento de projetos de inovação e de sua característica mais marcante - ser inédito - e apoiado na vasta literatura de gerenciamento ágil e sua abordagem fortemente marcada pelo trabalho com iterações, este trabalho propõe um novo método ágil de condução de iterações, intitulado Rush, que visa minimizar as entregas fora do prazo, ou seja, reduzir o atraso dos projetos, sobretudo aqueles com alto grau de inovação. Para cumprir tal objetivo, o método aborda questões como: caos antes do planejamento; criatividade e superação; comunicações individuais; redução de requisitos e aumento de custo para cumprir prazos; focaliza a entrega ao invés do escopo; além da utilização de micros pulmões dentro das iterações. O método pretende auxiliar o líder e seu time durante a execução das iterações, dando ritmo e fluidez ao projeto, misturando técnicas, boas práticas e comportamental, podendo - e devendo - ser incorporado dentro das iterações de outros métodos mais amplos e conhecidos de gerenciamento de projetos e apoiado por uma cultura de gestão de projetos já consolidada na empresa onde será aplicado.

Palavras-Chave: Rush. Iteração. Inovação. Gerenciamento ágil. Prazo. 


\section{INTRODUÇÃO}

A inovação tecnológica é o principal caminho para o aumento da competitividade das empresas. Essa inovação pode se dar de diversas formas, como inovação de produto (hardware), inovação de sistemas (software), inovação de processos etc. Porém, como se trata de inovação, o princípio básico é que o projeto em questão seja inédito e, consequentemente, não possua histórico de desenvolvimento nem base de comparação, informações estas que são necessárias para a utilização dos métodos clássicos de gerenciamento de projeto.

Foi envolto com essa problemática que os métodos de gerenciamento ágil surgiram, tendo como marco histórico a publicação do manifesto para desenvolvimento ágil de software em 2001. Um dos principais conceitos dos métodos de gerenciamento ágil de projetos é o trabalho por iterações, ou seja, dividir longos e complexos planejamentos em micros planejamentos, dando um passo porvez na direção do objetivo final do projeto e utilizando o aprendizado adquirido na iteração anterior para planejar o próximo ciclo. Diversos métodos consagrados utilizam este conceito, contrapondo o gerenciamento clássico que geralmente prescreve um grande e único esforço de planejamento no início do projeto.
Porém, dentre os métodos mais difundidos no mercado, a iteração costuma ser composta por uma única fase, um único período, executada da mesma forma e no mesmo ritmo de seu início ao fim. Nessa linha de condução, dentro da iteração, poucas são as técnicas e formas de tratar os problemas de percurso, sejam eles de ordem tecnológica, pessoal, ambiental, política etc., cabendo somente à próxima iteração o tratamento desses problemas.

Como imprevistos das mais diversas naturezas são muito comuns em projetos, sobretudo nos de inovação, muitas iterações finalizam sem que suas entregas sejam feitas na totalidade, ocasionando atrasos sistemáticos para o projeto.

O objetivo deste trabalho é propor um novo método ágil, objetivo e simples de trabalho com iterações, baseado em entregas e não em tarefas, aderente à dinâmica de projetos de inovação, ou seja, alto grau de incertezas, que potencialize entregas dentro do prazo e propicie desempenho para o projeto e satisfação para o cliente, reduzindo, assim, os atrasos tão frequentes em projetos de inovação.
Dentro dA TEMÁtica de

GERENCIAMENTO ÁGIL, CADA

MÉTODO CONECTA SUA ITERA-

ÇÃO AOS DEMAIS PROCESSOS

DO PROJETO DEfININDO INTER-

FACES DE ENTRADA E SAÍDA,

PRAZOS, METAS ETC. 


\section{MÉTODO RUSH}

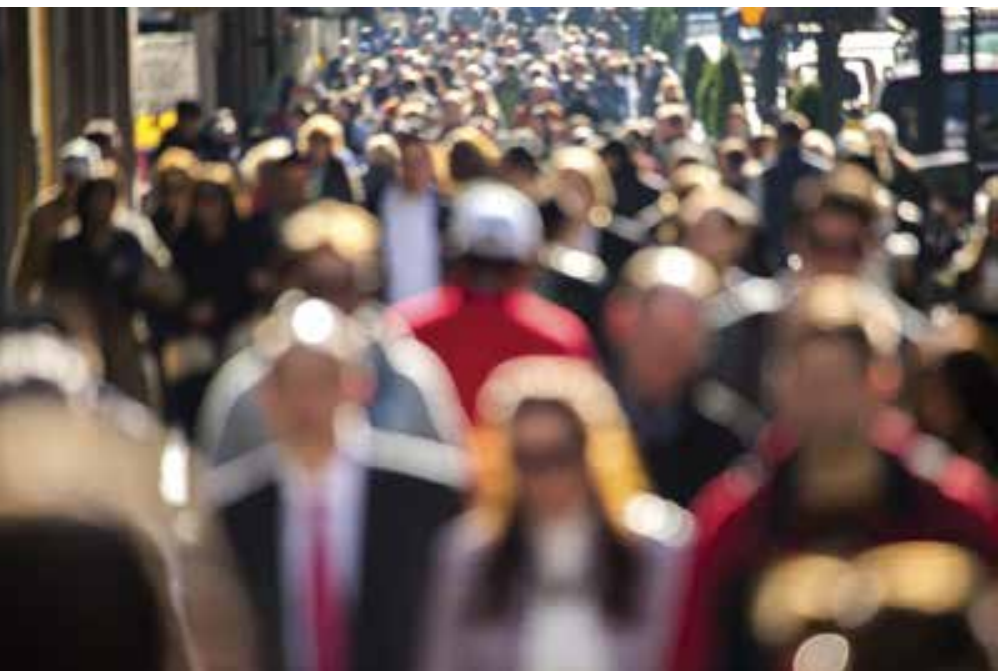

O nome Rush ${ }^{1}$ não é um acrônimo, mas uma palavra que expressa a intensidade do método e a sua busca pelo tempo. Este capítulo descreve o método em detalhes, abordando suas fases, seus conceitos, suas técnicas, boas práticas e forma de utilização.

Para conduzir este método, necessita-se de um líder de projeto, ao invés de um gerente de projetos, pois sua principal função é motivar, instigar, remover obstáculos, estabelecer metas e entregas, utilizando o seu tempo, mais com as pessoas e menos com as tarefas, com documentos e burocracia. Highsmith (2009, p.48) cita que "em um projeto ágil, o time cuida das tarefas e o líder de projeto cuida do time", e "a real autoridade de um líder não é delegada de cima para baixo, mas conquistada de baixo para cima”.
Cabe ressaltar que o método aqui proposto pode - e deve - ser utilizado dentro de outro método mais abrangente de gerenciamento de projetos (como por exemplo o Scrum), que utilize o conceito de iterações, assim como pode ser alterado e aprimorado para que melhor se encaixe com as necessidades de cada projeto, método, empresa ou líder de projeto, sendo importante que sua aplicação seja apoiada por uma cultura de gestão de projetos já consolidada na empresa ou instituição em questão.

O Rush é composto por quatro fases e cada uma delas cumpre um objetivo específico e a priori, possuindo duração igual, podendo variar de um a cinco dias cada ${ }^{2}$. A iteração possui sempre a meta de fazer uma ou mais entregas, sendo que essa entrega deve ser dimensionada pelo líder de projeto para a duração de três fases (Caos\#; Ação! e Superação?) ${ }^{3}$, ou seja, a equipe de projeto focaliza sempre o final da fase de Superação, conforme ilustra a figura 1 , enquanto a entrega (de fato) para o cliente (seja ele interno ou externo) é acordada para o final da quarta fase (Pulmão\$). O objetivo aqui sempre é "ganhar" o pulmão, ou seja, não usá-lo e ter a possibilidade de adiantar o projeto e surpreender positivamente o cliente.

\footnotetext{
${ }^{1}$ Segundo tradução (inglês-português) do dicionário Michaelis (2014), Rush significa: ímpeto, investida, arremetida; movimento rápido, avanço; pressa, precipitação, agitação, afobação; fúria, torrente.

${ }^{2}$ Em iterações curtas, com fases de um dia, para fechar uma semana, a sugestão é dobrar a segunda fase (Ação!).

${ }^{3}$ A pontuação faz parte do nome, com o objetivo de estabelecer uma identidade visual.
} 
Figura 1: Iteração composta de quatro fases - Método Rush

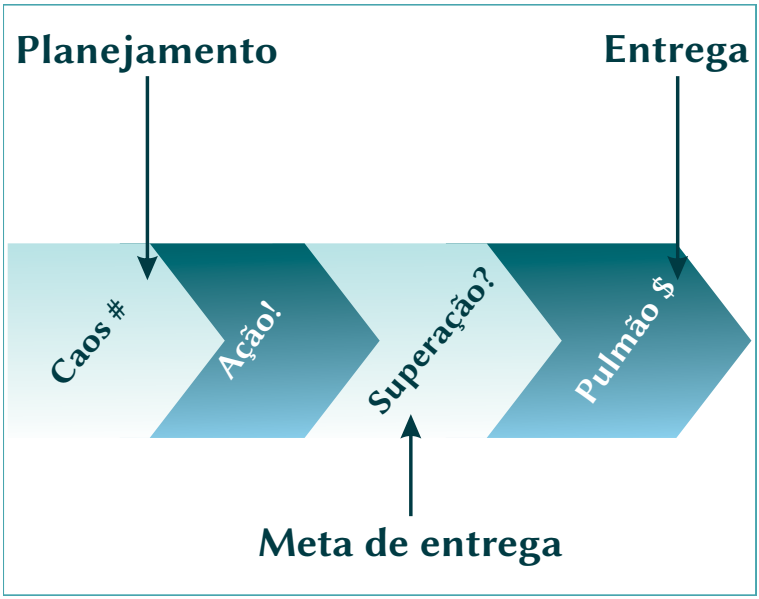

Fonte: Dos autores (2014)

Nesse contexto, a correta definição da entrega - sua complexidade e tamanho - torna-se essencial para o sucesso da iteração. Dessa forma, visualizando o projeto como um todo, a soma das entregas das iterações deve ser igual ao produto final do projeto:

\section{Produto Final $=$ Entrega $1+$ Entrega $2+\ldots+$ Entrega $n$}

A iteração inicia com uma reunião com todo o time de projeto, em que o líder comunica a entrega à equipe, detalhando requisitos, funções, qualidade, custos etc., além de tirar dúvidas, repassar as expectativas do cliente (seja ele interno ou externo) e,principalmente, estabelecer a duração da iteração e suas fases. Para essa reunião, recomenda-se a utilização de imagens, desenhos, diagramas e outras formas gráficas de comunicação, além de texto, para que todos os membros da equipe tenham o mesmo entendimento da entrega.

Uma vez comunicada e acordada a entrega, inicia-se a primeira fase do método, o Caos. A seguir são detalhadas as quatro fases que compõem o método Rush.

\section{a) FASE 1: CAOS \#}

Esta fase traz princípios da etapa de Especulação e Exploração ${ }^{4}$ de Highsmith (2009) e do método de construção da visão de produto (PVMMProduct Vision Management Method) de Amaral et al. (2011), principalmente em relação às preconcepções; porém, em uma nova abordagem, seguindo um ciclo específico composto por: Pesquisar, Testar e Planejar (ciclo PT\&P, conforme ilustrado na figura 2).

Figura 2: Ciclo PT\&P

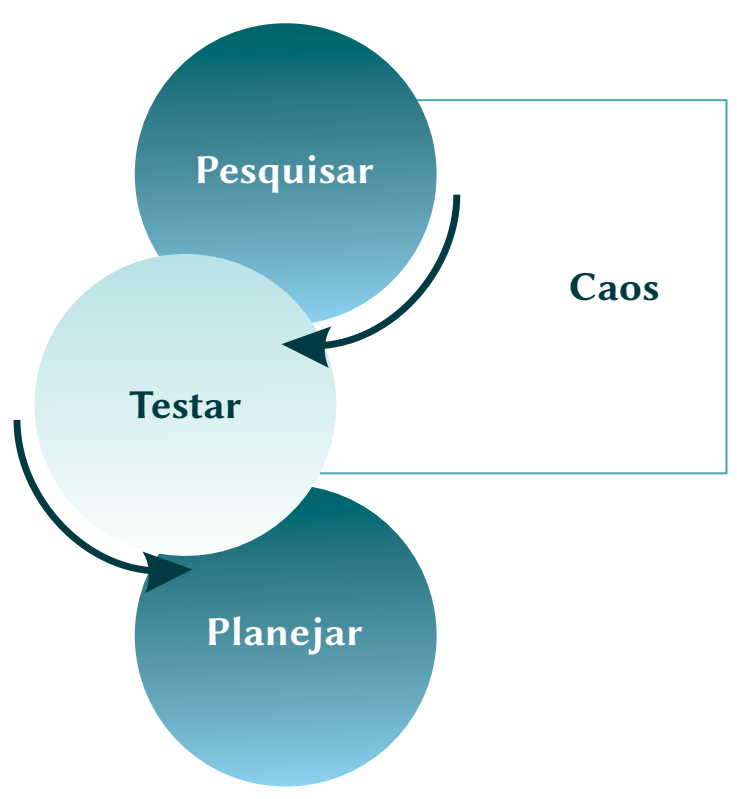

Fonte: Dos autores (2014)

O ciclo é composto por três etapas, em que: (a) pesquisa-se soluções para a problemática envolvida na entrega, (b) testa-se os conceitos e as soluções encontradas para se ter uma boa ideia se funcionará e, por fim, (c) planeja-se as fases seguintes com base no aprendizado adquirido nas etapas anteriores. As etapas (a) e (b) podem ocorrer inúmeras vezes, até que se tenha subsídios suficientes ${ }^{5}$ para prosseguir para a etapa (c) de planejamento.

\footnotetext{
${ }^{4}$ Highsmith (2009) descreve um framework composto de cinc etapas: Envision, Speculate, Explore, Adapt e Close.

${ }^{5}$ Limitando-se ao tempo disponível dentro da primeira fase da iteração.
} 
Nota-se que praticamente $1 / 3$ do tempo que se possui para fazer a entrega, ou seja, esta primeira fase,é destinada ao pensamento livre, à pesquisa e a testes de hipóteses e só depois se inicia o planejamento.

\section{PODE-SE DEfINIR - COLOQUIAL-}

MENTE - ESTA FASE COMO:

"VAMOS TENTAR VÁRIAS COISAS

E VER NO QUE VAI DAR, VER O

QUE FUNCIONA PARA A NOSSA

ENTREGA, DEPOIS SENTAMOS

E PLANEJAMOS O QUE FAZER,

COMO FAZER E QUEM IRÁ

EXECUTAR". É ISSO O QUE O

CICLO PTEP PRESCREVE, UM

POUCO DE CAOS ANTES DO

PLANEJAMENTO.
Para esta primeira fase, tem-se como premissa que a entrega já foi estabelecida ${ }^{6}$ - é o ponto de partida da iteração - e o caos aqui citado é uma forma de trabalho livre e criativo de todos os membros da equipe de projeto, porém orientados ao mesmo fim, a entrega dentro do prazo. Dessa forma, muitas ações que fariam parte do planejamento e do próprio desenvolvimento do projeto acabam sendo executadas (ou preparadas) dentro do ciclo PT\&P, tornando esta fase não só criativa, mas também produtiva e contributiva em direção à meta.

A fase de Caos finaliza com o planejamento da iteração ${ }^{7}$ e para esta etapa existem diversas ferramentas - em conjunto ou individual amplamente conhecidas (ex.MSProject, Excel, Post it etc.) e que podem ser aplicadas neste momento, priorizando-se sempre a simplicidade, objetividade e o domínio da ferramenta pelos usuários.

O papel do líder de projeto nesta etapa (planejamento) é o de reunir o time, promover uma discussão sobre as soluções encontradas, sanar dúvidas e auxiliar os membros da equipe a se auto-organizarem. Nota-se que o líder não constrói nem distribui listas de tarefas, isso é atribuído ao próprio time de projeto, que ao encerrar o planejamento deve ter claro o que deve ser feito nas próximas duas fases (Ação! e Superação?) para que a entrega seja feita ao final da fase de Superação, pois esta é a meta interna da equipe.

\footnotetext{
${ }^{6}$ Por exemplo, utilizando-se Scrum, a entrega é estabelecida na Sprint Planning Meeting, através da seleção da Sprint Backlog.

${ }^{7}$ Reunião R2, descrita em detalhes no Plano de Comunicação.
} 


\section{b) FASE 2: AÇÃO!}

Consiste em colocar em prática o planejamento da primeira fase, ou seja, "mãos à obra"; daío motivo da exclamação no nome da fase, transmitir trabalho,intensidade e transpiração.Parte-se do princípio amplamente recomendado ${ }^{8}$ no APM de trabalhar com times maduros e auto-organizados, não sendo necessários métodos e/ou ferramentas adicionais de controle.

Devido à pouca estruturação desta fase e à liberdade de trabalho da equipe, a atenção do líder de projeto deve ser voltada para o Plano de Comunicação, que se constitui item fundamental do método proposto.

Ao final desta fase, a equipe, juntamente com seu líder de projeto, faz uma avaliação do ritmo e avanço do projeto em direção à entrega da iteração.

\section{PARA ESTA AVALIAÇÃo SE FAZ UMA PERGUNTA PARA CADA MEMBRO DO TIME (O LÍDER DE PROJETO TAMBÉM RESPONDE): "VOCÊ ACREDITA QUE COM MAIS UMA FASE VAMOS CON- CLUIR A ENTREGA?".}

Se a maioria absoluta responder assertivamente, isso indica que o ritmo e avanço do projeto estão adequados. Caso contrário, medidas de correção de rota (replanejamento) deverão ser tomadas ${ }^{9}$, antes do início da fase de Superação.

\section{c) FASE 3: SUPERAÇÃO?}

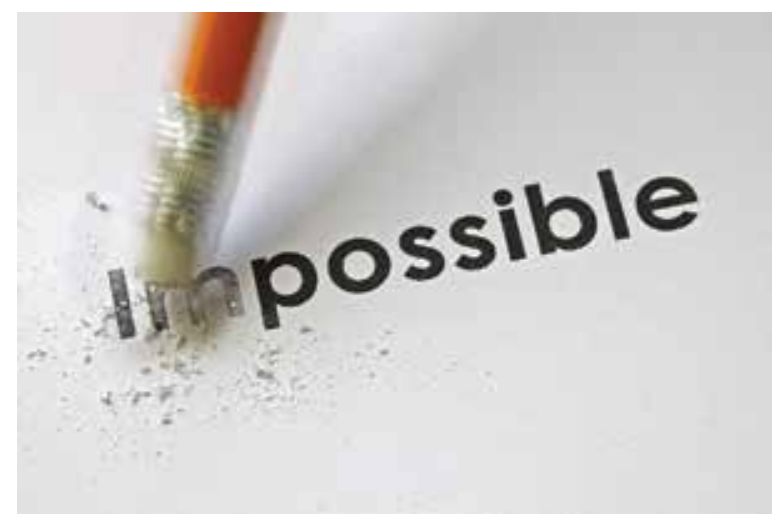

A entrega da iteração deve ser feita ao final desta fase. Dessa forma, se a análise de ritmo e avanço $\mathrm{da}$ fase anterior indicarem para conclusão da entrega ao final da terceira fase, o projeto deve seguir seu andamento normal, e esta fase tornase uma continuação da fase de Ação.

Caso contrário - e daí a interrogação no nome da fase - a criatividade, o empenho e a superação do time e de seu líder se fazem necessários, focando em realizar a entrega no prazo, mesmo que tenha que abrir mão de requisitos ou aumentar custos. Este é um ponto conceitual, polêmico e bastante importante do método, pois posiciona requisitos (escopo) e custos em segundo plano e faz com que toda a equipe se preocupe em encontrar formas de fazer a entrega dentro do prazo.

Diante da tríplice restrição em projetos (Escopo, Custo e Prazo), o método Rush define como única prioridade o prazo e trabalha com o escopo e custo como variáveis do gerenciamento de projeto, dando ao líder do projeto um alto grau de autonomia e responsabilidade. Neste ponto, cabem duas ressalvas importantes:

\footnotetext{
${ }^{8}$ Amaral et al. (2011); Highsmith (2009).

${ }^{9}$ Reunião R3, descrita em detalhes no Plano de Comunicação.
} 
- Alguns requisitos de qualidade não são negociáveis (como normas de segurança em aviação, medicina etc.) e a disponibilidade financeira é finita; dessa forma, cabe ao líder de projeto trabalhar com as variáveis dentro do seu nível de autoridade e restrições.

- Alterações fora do nível de autoridade do líder de projeto só devem ser implementadas se acordadas com o cliente, que deve sempre ser envolvido neste momento.

Desta forma, abandonar requisitos e colocar a qualidade ${ }^{10} \mathrm{em}$ segundo plano não é uma tarefa elementar e deve seguir uma ordem hierárquica de prioridade, visando impactar o mínimo possível nas demais iterações do projeto e focando no que é realmente importante, essencial. Esta abordagem já é utilizada no método XP, que usa controle de qualidade como variável de projeto, adiando ou cancelando funcionalidades menos valorizadas em prol da produtividade.

Corroborando as ideias aqui apresentadas, Huang et al. (2012, p. 8), dentre uma série de sete recomendações para promover a agilidade no desenvolvimento de projetos, citam "que se deve analisar e testar o mais cedo possível para atenuar problemas e que especificações e requisitos serão trabalhados ao longo do desenvolvimento do projeto".

Analisando custo como variável do sistema, existem diversas possibilidades de ação, tais como: aumento da força de trabalho (seja em número de pessoas ou horas extras), contratação de empresas ou especialistas, compra de tecnologia e conhecimento etc., possibilidades estas que, num primeiro momento, representam aumento de custos do projeto, mas, ao garantirem a entrega no prazo, podem compensar perdas futuras relacionadas ao custo da perda de uma oportunidade de mercado ou uma janela de lançamento de produto. Cabe lembrar também que o simples fato de manter um projeto em execução, além do seu cronograma planejado, representa aumento de custo para seu financiador, fazendo mais sentido, caso seja necessário, investir esses recursos para garantir o cumprimento do prazo.

Também é necessário se ter a percepção de que a iteração e, consequentemente, sua entrega fazem parte de algo maior - o projeto - e que realizar a entrega no prazo faz com que o projeto avance (a equipe aprenda etc.) e que custos serão compensados, assim como requisitos preteridos num primeiro momento, se necessário, serão atendidos em seguida (nas próximas iterações), pois qualidade se conquista e se aprimora durante o projeto, já tempo perdido não se recupera nunca mais.

\section{d) FASE 4: PULMÃO \$}

A quarta fase do Rush é o "pulmão" da iteração e,consequentemente, do projeto. Ela representa $1 / 4$ da iteração, ou seja, 25\% de "pulmão", o que para projetos de inovação é uma taxa bastante pequena, porém coerente, pois ao se trabalhar com micro ajustes dentro da iteração, não se deixa problemas ou erros serem propagados no projeto e assim se consegue melhorar a assertividade das entregas.

A exemplo do que Goldratt e Cox (2003) aborda na Teoria das Restrições - identificar os gargalos, ou seja, o elo mais fraco da cadeia, aquele que limita a capacidade do sistema e atuar sobre ele, mudando-o de lugar e subordinando todo o resto a esta decisão -, o Rush propõe algo parecido quando traz os longos ajustes do final do projeto para dentro da iteração, numa

${ }^{10}$ A qualidade a que este trabalho se refere está associada à qualidade externa, na definição de Kniberg (2007). 
abordagem de micros pulmões, mudando a restrição de lugar, e assim fazendo uma distribuição mais homogênea do fluxo do projeto.

\section{Cabe lembrar que o objetivo do Rush é "ganhar" o Pulmão ${ }^{11}$, ou seja, atingir a meta de entrega interna no final da fase de Superação.}

Se esse objetivo for atingido, tem-se o cenário 1 (ideal) do quadro 1 , caso contrário, o Pulmão deve ser utilizado conforme o cenário em questão, visando à entrega acordada com o cliente, ainda dentro do prazo.

Quadro 1: Formas de condução da fase Pulmão

\begin{tabular}{|c|l|l|}
\hline Cenário & \multicolumn{1}{|c|}{ Status (fase anterior) } & \multicolumn{1}{c|}{ Condução } \\
\hline 1 & Entrega foi realizada de forma plena. & $\begin{array}{l}\text { Fase pode ser cancelada ou utilizada para } \\
\text { testes. }\end{array}$ \\
\hline 2 & $\begin{array}{l}\text { Entrega foi realizada com redução de } \\
\text { requisitos. }\end{array}$ & $\begin{array}{l}\text { Fase se concentrará em atingir a entrega } \\
\text { plena (todos os requisitos). }\end{array}$ \\
\hline 3 & Entrega não foi realizada. & Utiliza-se o Pulmão para realizar a entrega. \\
\hline
\end{tabular}

Fonte: Dos autores (2014)

Ao final desta quartafase-ou em determinados casos, até mesmo antes dela ${ }^{12}$ - a iteração finaliza, a entrega é realizada e uma nova iteração se inicia. Apesar da fase de Pulmão e de todos os demais cuidados e práticas do método, caso a entrega não seja feita (o que pode acontecer), esta deve ser revista antes de compor a meta de entregas da próxima iteração.

Na sequência,são apresentadas práticas importantes relacionadas à comunicação dentro do projeto, por meio de uma proposta de Plano de Comunicação, essencial para uma correta utilização do método e atingimento de suas metas.

\section{e) PLANO DE COMUNICAÇÃO}

O plano de comunicação é parte fundamental do método proposto, pois é por meio de uma rotina de cinco reuniões estruturadas ( $\mathrm{R} 1 \mathrm{a}$ R5) com toda a equipe de desenvolvimento e sob condução do líder de projeto, que as fases se interligam e o fluxo do método acontece, conforme ilustra a figura 3.

Figura 3: Rotina de reuniões com toda equipe de projeto

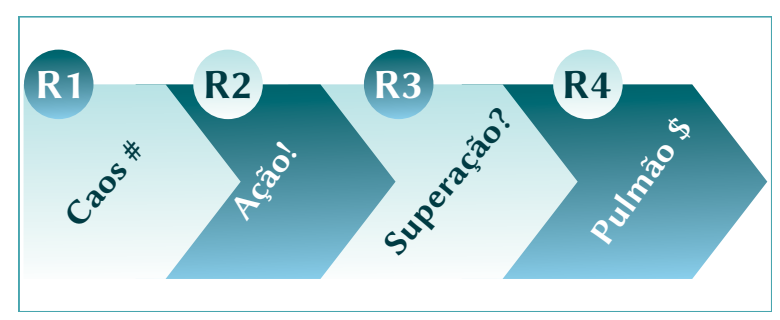

Fonte: Dos autores (2014)

\footnotetext{
${ }^{11} \mathrm{O}$ cifrão (\$) que acompanha o nome da fase busca reforçar a percepção de ganho, quando não se necessita utilizar o Pulmão.

${ }^{12}$ No caso do Cenário 1 do quadro 1.
} 


\section{- Reunião R1:}

O Rush inicia com a reunião R1, em que o líder de projeto reúne sua equipe para discutir e definir a entrega ${ }^{13}$, detalhando requisitos, funções, custos, expectativas do cliente e, sobretudo, o prazo. É nessa reunião que se define a duração da iteração: recomenda-se que fique entre uma e quatro semanas e a duração de suas fases de um a cinco dias cada, procurando manter as fases todas do mesmo tamanho.

\section{A PREOCUPAÇÃO PRINCIPAL}

DO LÍDER DEVE SER DEfiNIR A

ENTREGA COMPATÍVEL COM O

TEMPO E TAMANHO/QUALIfi-

CAÇÃO DE SUA EQUIPE, TENDO

COMO META INTERNA O FINAL

DA FASE DE SuPERAÇÃO, ALÉM

DE GARANTIR QUE TODOS TE-

NHAM A MESMA COMPREENSÃO

DA ENTREGA.

Preconcepções da solução e desenhos da entrega são altamente recomendados nesta reunião.

\section{- Reunião R2:}

A reunião R2 é o momento pós caos, onde ocorre o planejamento da iteração. Inicia-se ouvindo as pesquisas, os testes e principalmente as formas de solução da problemática da entrega, encontradas e/ou sugeridas por cada membro da equipe técnica.

\section{O LÍDER NESTA REUNIÃO DEVE}

BUSCAR O CONSENSO DA EQUIPE

EM TORNO DA MELHOR SOLU-

ÇÃO, TECNOLOGIA E ESTRATÉGIA

PARA ATINGIR OS OBJETIVOS DA

ITERAÇÃO.

Feita a escolha do melhor caminho, a equipe técnica deve formalizar um planejamento para atingimento da meta, nas próximas duas fases (Ação! e Superação?). A ferramenta utilizada para o planejamento élivre e deve ser uma escolha da própria equipe, porém recomenda-se no mínimo a criação de uma lista de atividades, sua ordenação no tempo (por pré-requisito, prioridade etc.) e distribuição ${ }^{14}$ entre os envolvidos.

\section{- Reunião R3:}

Entre as fases de Ação e Superação acontece a reunião $\mathrm{R} 3$, que tem como primeiro objetivo medir o ritmo e desempenho da iteração como forma de estimar se a entrega será de fato feita ao final da próxima fase. Uma forma simples de fazer esta avaliação é formular a seguinte pergunta para cada membro do time de projeto (inclusive para o líder): "Você acredita que com mais uma fase vamos concluir a entrega?”. Se a maioria absoluta responder assertivamente, tem-se um bom indicador de fluxo de projeto e a reunião pode ser encerrada ou seu tempo pode ser utilizado para outras discussões pertinentes ao projeto. Se as respostas positivas não atingirem a maioria absoluta, este será um indicador que medidas adicionais e urgentes devem ser

\footnotetext{
${ }^{13}$ Cabe ressaltar que pode-se ter mais de uma entrega por iteração, ou seja, múltiplas metas e objetivos.

${ }^{14}$ A distribuição pode ser toda de uma vez, ou diariamente conforme o andamento das atividades.
} 
tomadas para convergir a entrega para a meta, ou seja, faz-se necessário um replanejamento da iteração. Neste cenário, configura-se o segundo objetivo da R3 - discutir o que precisa ser feito para garantir a entrega no prazo e não procurar encontrar justificativas para o atraso. As variáveis custo e requisitos (escopo) devem ser trabalhadas à exaustão, conforme descrito na Fase de Superação.

\section{- Reunião R4:}

A reunião R4 é o momento da entrega interna do time de projeto. O líder faz o papel do cliente (seja ele interno ou externo), verificando o que está sendo entregue, com o que foi estabelecido na reunião $\mathrm{R} 1$, sendo que o principal objetivo desta reuniãoé decidir o que fazer com a próxima fase (Pulmão\$). Para auxiliar a decisão do líder, três cenários e suas conduções são apresentados no quadro 1. Caso a iteração se encaixe nos Cenários 2 ou 3, um novo planejamento deve ser elaborado - nos moldes da reunião R3 com foco em cumprir a entrega com o cliente (de fato), ao final da fase de Pulmão, ou seja, ainda dentro do prazo da iteração.

\section{- Reunião R5:}

A iteração finaliza formalmente com a reunião $\mathrm{R} 5^{15}$, que possui dois momentos distintos. $\mathrm{O}$ primeiro (R5a) é onde a entrega é apresentada e validada pelo cliente, sendo um momento importante para o time obter retorno sobre a satisfação e expectativas do cliente sobre o projeto. Para registro da validação, recomenda-se a utilização de um termo de aceite da entrega. No segundo momento (R5b), sem a presença do cliente, o time faz uma reunião de retrospectiva ${ }^{16}$ para avaliar os pontos positivos e negativos da iteração que finalizou, além de discutir e implementar o que precisa ser melhorado e, sobretudo, assimilar e difundir as lições aprendidas.

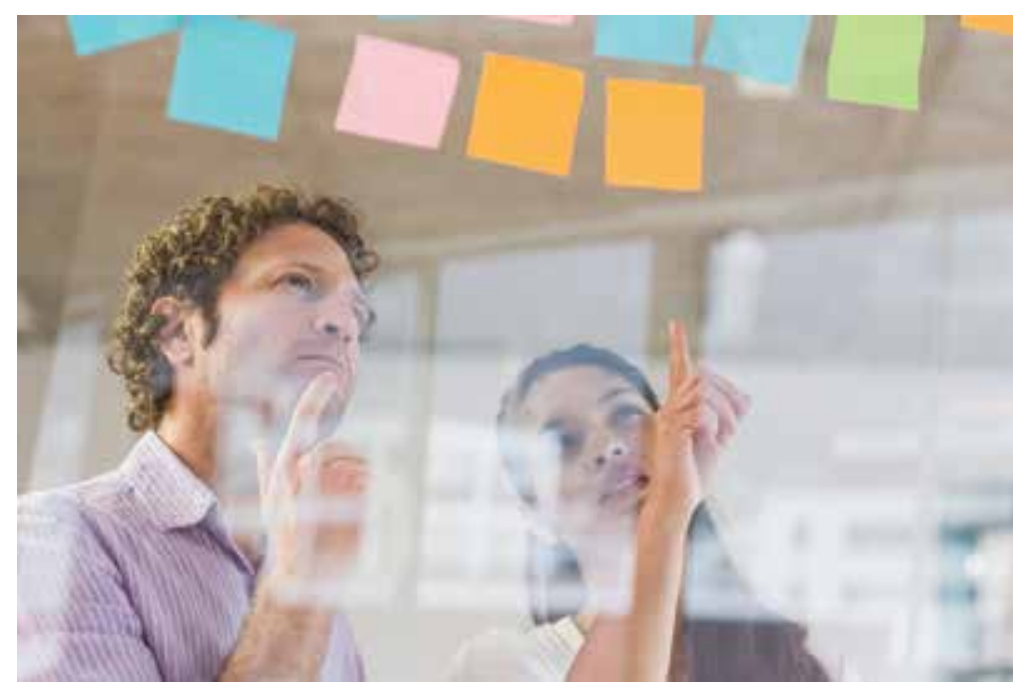

\section{- Reuniões de Feeds:}

Como pano de fundo para o plano de comunicação e para todo o método Rush - mas não menos importante-, recomenda-se que o líder de projeto tenha uma rotina de reuniões diárias (feeds).Os Feeds são reuniões informais de cinco a dez minutos, sem horário e local predeterminado, em que o líder procura individualmente cada membro da sua equipe de projeto para conversar. A postura do líder nesta conversa é mais de ouvir, deixando seu interlocutor à vontade para relatar seus avanços, suas dúvidas, dificuldades e seus conflitos. Sobre os avanços, o líder deve analisar se estão em linha com os objetivos da entrega e, neste caso, incentivar e motivar o colaborador; caso contrário, deve atuar esclarecendo a entrega e corrigindo o rumo das atividades. Além disso, o líder deve buscar sanar as dúvidas, remover os obstáculos e conciliar os conflitos (sobretudo os de ordem pessoal), por isso a importância da conversa individual e reservada. Apesar de informal,

\footnotetext{
${ }^{15}$ Existe a possibilidade, inclusive almejada pelo método, de a entrega ter sido feita na reunião R4 e a fase de Pulmão ser cancelada. Dessa forma, a reunião R5 acontece na sequência da R4.
}

${ }^{16}$ Nos mesmos moldes da reunião de retrospectiva do método Scrum. 
os Feeds não devem ser confundidos com as conversas corriqueiras que o time costuma ter diariamente durante a execução do projeto.

Cabe relembrar que o método Rush deve ser utilizado dentro de um método mais abrangente de gerenciamento de projetos, e que o plano de comunicação aqui apresentado não é excludente de outras práticas de comunicação, como por exemplo o daily meeting ${ }^{17}$ do Scrum, que pode ser utilizando junto com os Feeds e reuniões $\mathrm{R} 1$ a $\mathrm{R} 5$.

Por exemplo,em casos de iterações curtas, como uma semana, as próprias reuniões $\mathrm{R} 1$ a $\mathrm{R} 5$ proporcionarão o momento diário de união de todo o time, porém com um pouco mais de tempo e, neste caso, o daily meeting pode ser feito junto, ou dentro, das reuniões do Rush. Já em iterações maiores, como um mês, no Rush se tem a união do time somente uma vez na semana e, sendo o Scrum o método principal, o daily meeting pode ser normalmente executado, concomitantemente aos Feeds.

Dessa forma, caberá a cada líder de projeto escolher qual será o plano de comunicação que melhor se adequa a sua empresa, equipe e projeto.

Como forma de compilação da rotina de reuniões apresentada, o quadro 2 fornece um resumo do plano de comunicação do Rush.

Quadro 2: Resumo do plano de comunicação

\begin{tabular}{|c|c|l|}
\hline Reunião & Duração ${ }^{18}$ & \multicolumn{1}{c|}{ Descrição } \\
\hline Feed & 5 a 10 min. & $\begin{array}{l}\text { Informal, em par (líder e membro da equipe). Foco no acompa- } \\
\text { nhamento do projeto. Poucos ou nenhum registro. }\end{array}$ \\
\hline R1 & 30 a 60 min. & $\begin{array}{l}\text { Formal, com todo o time (o cliente é bem-vindo). Comunicar a } \\
\text { entrega detalhadamente e esclarecer dúvidas. Registros simples. }\end{array}$ \\
\hline R2 & 45 a 90 min. & $\begin{array}{l}\text { Formal, com todo o time. Apresentação dos resultados das } \\
\text { pesquisas e dos testes (caos), escolha da melhor estratégia e } \\
\text { planejamento da iteração. Registros simples. }\end{array}$ \\
\hline R3 & 05 a 45 min. & $\begin{array}{l}\text { Formal, com todo o time. Avaliação de ritmo e desempenho do } \\
\text { projeto e replanejamento, caso necessário. Registros simples. }\end{array}$ \\
\hline R4 & 30 a 60 min. & $\begin{array}{l}\text { Formal, com todo o time. Validação interna da entrega e repla- } \\
\text { nejamento, caso necessário. Registros simples. }\end{array}$ \\
\hline R5a & 30 a 60 min. & $\begin{array}{l}\text { Formal, com o cliente. Para aceite da entrega, acompanhamento } \\
\text { e projeto e alinhamento da próxima entrega. Registros simples } \\
\text { assinatura do termo de aceite da entrega. }\end{array}$ \\
\hline R5b & 30 a 60 min. & $\begin{array}{l}\text { Formal, com todo o time. Reunião de retrospectiva e lições } \\
\text { aprendidas. Registros simples. }\end{array}$ \\
\hline
\end{tabular}

Fonte: Dos autores (2014)

\footnotetext{
${ }^{17}$ Reuniões diárias de 15 minutos com todo o time do projeto para discutir o que foi feito no dia anterior e priorizar as atividades do dia que se inicia.

${ }^{18}$ Conforme duração da iteração (de uma a quatro semanas), tamanho da equipe e complexidade da entrega.
} 
Com o plano de comunicação, finaliza-se o detalhamento do método Rush, permitindo que este seja inserido no contexto de gerenciamento ágil das empresas.

\section{f) BOAS PRÁTICAS DO RUSH}

O método Rush é um guia de condução de iterações que possui embasamento em algumas importantes boas práticas de gerenciamento ágil de projetos. Este capítulo finaliza com a compilação das oito principais boas práticas abordadas pelo Rush e um breve comentário sobre cada uma delas (apresentadas no quadro 3).

Quadro 3: Boas práticas do Rush

\begin{tabular}{|c|c|}
\hline \multicolumn{2}{|r|}{ Boa prática } \\
\hline $\begin{array}{l}\text { Caos antes do } \\
\text { planejamento }\end{array}$ & $\begin{array}{l}\text { Dar à equipe um momento de liberdade e criatividade antes de iniciar } \\
\text { o planejamento formal da interação. Rodar o ciclo PT\&P. }\end{array}$ \\
\hline Menos burocracia & $\begin{array}{l}\text { Menos é mais. Menos burocracia traz mais agilidade, mais motivação, } \\
\text { mais foco, mais prazer e bem-estar ao time. No Rush, praticamente } \\
\text { não existem formulários, templates, tabelas ou quadros para serem } \\
\text { preenchidos. }\end{array}$ \\
\hline $\begin{array}{l}\text { Foco na entrega, } \\
\text { dentro do prazo }\end{array}$ & $\begin{array}{l}\text { Fornecer à equipe um único e claro objetivo, e trabalhar com todas } \\
\text { as demais variáveis para atingimento da meta. }\end{array}$ \\
\hline Replanejamento & $\begin{array}{l}\text { Não é preciso aguardar a finalização de uma iteração para saber que } \\
\text { ela não cumprirá seus objetivos, dessa forma, replanejar no meio do } \\
\text { caminho é melhor que seguir no caminho que não levará à entrega. }\end{array}$ \\
\hline Superação ${ }^{19}$ & $\begin{array}{l}\text { Atingir metas, muitas vezes, requer sacrifícios, obstinação, dedica- } \\
\text { ção e comprometimento extra, e a equipe Rush deve possuir essas } \\
\text { qualidades, pois elas serão necessárias em algum momento. Além de } \\
\text { uma boa dose de orgulho. }\end{array}$ \\
\hline Micro pulmões & $\begin{array}{l}\text { Trazer a fase dos ajustes (do final dos projetos) para próximo da } \\
\text { execução, fazendo com que as correções de rotas e atingimento de } \\
\text { metas ocorra dentro da iteração. }\end{array}$ \\
\hline $\begin{array}{l}\text { Gerenciamento } \\
\text { por entrega }\end{array}$ & $\begin{array}{l}\text { O líder de projeto não deve se preocupar com tarefas e atividades } \\
\text { (estas são preocupações do time de desenvolvimento), mas sim estar } \\
\text { atento se o "caminho" que a equipe está tomando os levará à meta } \\
\text { e, se necessário, agir. }\end{array}$ \\
\hline $\begin{array}{l}\text { Comunicação } \\
\text { individual }\end{array}$ & $\begin{array}{l}\text { Muitos dos problemas não aparecem nas reuniões em equipe, mas } \\
\text { isso não significa que não existem. Uma rápida conversa individual } \\
\text { propicia a oportunidade de virem à tona, assim como ajuda também } \\
\text { o líder a entender melhor seu time e questões técnicas do projeto. }\end{array}$ \\
\hline
\end{tabular}

Fonte: Dos autores (2014)

\footnotetext{
${ }^{19}$ Toda superação deve de alguma forma ser recompensada. Cabe ao líder descobrir o que é valor para cada membro da sua equipe e recompensá-lo com algo que realmente seja importante para ele.
} 
Diversos outros conceitos (valores, princípios e práticas) dos mais variados métodos ágeis como sentar-se junto, feedback constante, simplici dade, envolvimento do cliente etc., são muito bem alinhados com o Rush e devem, sempre que possível, ser utilizados.
O próximo capítulo apresenta a aplicação do Rush em um projeto de inovação envolvendo software e hardware.

\section{APLICAÇÃO E DISCUSSÃO DOS RESULTADOS}

Este capítulo apresenta a aplicação do Rush em um caso real de projeto de inovação, assim como faz uma análise do resultado, lista sua vantagens e limitações e apresenta as contribuições do método desenvolvido.

\section{Com o objetivo de testar na prática os conceitos do Rush, a equipe de inovação do Instituto SENAI de Tecnologia em Automação e TIC localizado em Florianópolis/SC, foi convidada para participar do experimento.}

O convite foi aceito e um projeto em execução foi selecionado para a aplicação, priorizando-se entregas que envolvessem software e hardware. Porse tratar de projeto real e que possui cláusulas de sigilo, o nome das empresas envolvidas, dos pesquisadores e alguns detalhes técnicos são omitidos, atendo-se mais à aplicação do método, ao plano de comunicação e a seus resultados.

\section{a) PROJETO - KIT DUAL FUEL}

O objetivo deste projeto é o desenvolvimento de um kit dual fuel, diesel/gás natural, para moto geradores a diesel, similar aos kits de conversão para GNV (gás natural veicular) de carros ciclo
$\mathrm{Otto}^{20}$. Este kit dual fuel deve ser adaptado nos moto geradores diesel, com o mínimo de intervenção mecânica e elétrica, permitindo que estes funcionem com uma mistura de diesel e gás natural, mantendo o desempenho de geração elétrica e diminuindo o custo com combustível (relação diesel versus diesel/gás).

Junto com o líder do projeto e dentre as diversas entregas que o projeto ainda tinha para cumprir, selecionou-se uma entrega que fosse possível de ser executada em três semanas (isto na visão do líder) por uma equipe composta por dois pesquisadores, compondo uma iteração total de quatro semanas.

Por se tratar de um método novo para a equipe de projeto, como preparação para a reunião $\mathrm{R} 1$, foi apresentado em detalhes o método aos pesquisadores em uma reunião prévia $(\mathrm{R} 0)$, de aproximadamente duas horas, em que, além dos conceitos do Rush, discutiu-se também os objetivos do experimento e a forma com que seria aplicado. Deu-se então início à iteração.

$\mathrm{Na}$ reunião $\mathrm{R} 1$, o líder reuniu sua equipe e comunicou a entrega que teria pela frente. A entrega foi a seguinte: implementação de um

\footnotetext{
${ }^{20}$ Motores à combustão de gasolina ou álcool.
} 
controlador eletrônico para o kit dual fuel, interligado com sensores e atuadores em bancada, conforme ilustrado na figura 4 .

Figura 4: Diagrama em blocos da entrega

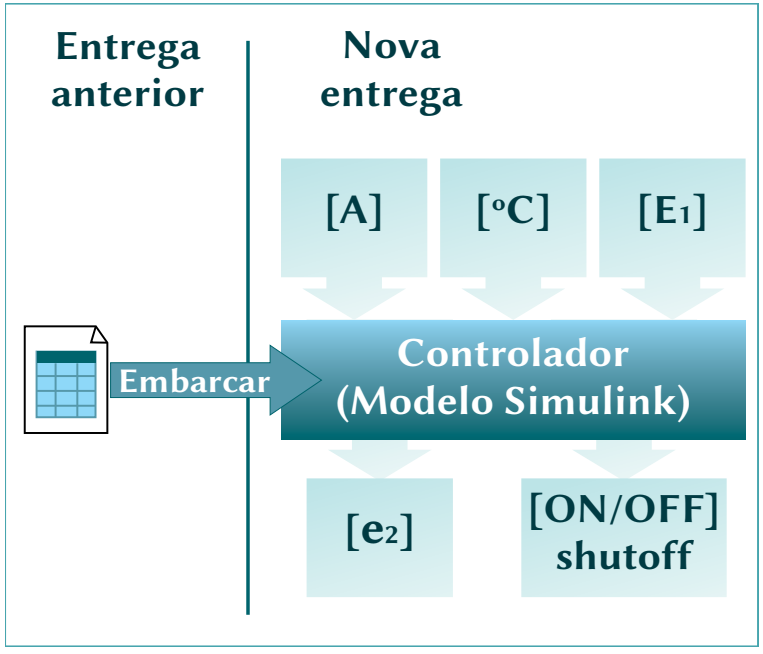

Fonte: Dos autores (2014)

Além de se utilizar da figura 4 para entendimento da entrega, o líder completou descrevendo funcionalidades e detalhando os requisitos da seguinte forma.

Resumo da entrega: escolher e embarcar em um sistema eletrônico, definido pelo time, o modelo computacional de controle do kit dual fuel previamente desenvolvido no ambiente Simulink. O controlador deverá estar interligado com sensores e atuadores do kit que serão testados em bancada por meio de uma lista de instruções.

\section{Requisitos funcionais e qualitativos:}

- Ler três sensores que permitam conhecer:

- [A] A temperatura (faixa mínima de $\left.0-600^{\circ} \mathrm{C}\right)$;

- $\left[{ }^{\circ} \mathrm{C}\right]$ Corrente em uma linha trifásica (mínimo de 300A por fase);
- $\quad[\Theta f]$ Abertura da borboleta (de acordo com o datasheet).

- Atuar em dois componentes da linha de gás:

- $[\Theta a]$ Borboleta eletrônica: enviar o comando eletronicamente;

- $\quad$ [ON/OFF] Válvula de shutoff: enviar o comando eletronicamente.

Comunicada a entrega e esclarecidas as dúvidas da equipe quanto ao entendimento das questões técnicas e objetivos da iteração, o líder encerrou a reunião $\mathrm{R} 1$, dando início à fase de Caos.

Durante a primeira semana da iteração (Caos\#), o líder buscou fazer as reuniões de Feed diariamente; vezes presencial, vezes por telefone em virtude de compromissos externos, e os pesquisadores se empenharam em buscar a melhor solução tecnológica para a entrega, visando aos recursos e prazo que tinham à disposição.

Ao final do Caos, aconteceu a reunião $\mathrm{R} 2$, onde foram discutidas ideias, conceitos e técnicas pesquisadas, além dos testes realizados pelo time. Os pesquisadores trouxeram de forma conjunta a proposta de solução, criando duas frentes de desenvolvimento (sub-entregas) que deveriam no final convergir para a entrega da iteração: Software de controle embarcado e Hardware (controlador lógico programável, mais sensores e atuadores). Como forma de organização das ideias discutidas, o líder utilizou uma lousa, onde foi construindo com seu time uma visão técnica da solução. A lousa foi fotografada (figura 5) e, na sequência, foi utilizada para a construção da lista de atividades da iteração. 
Figura 5: Visão técnica da solução

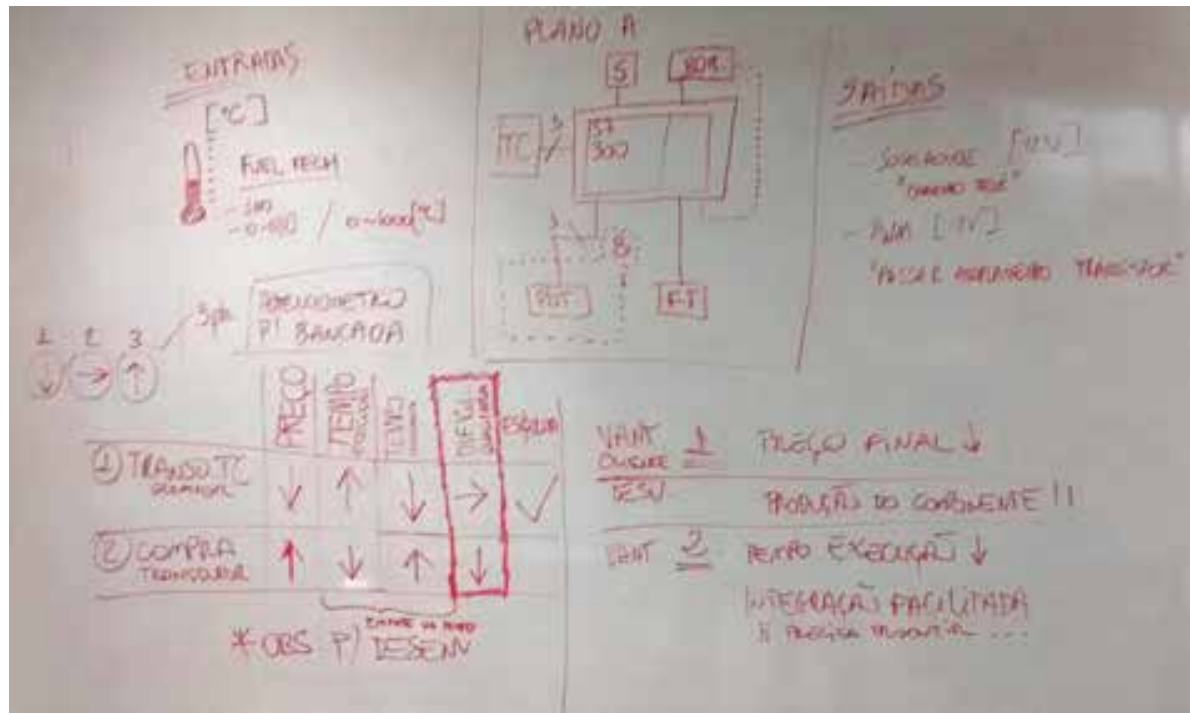

Fonte: Dos autores (2014)

Para validar se a solução proposta pelo time estaria adequada ao prazo da entrega e capacidade homem/hora disponível, novamente utilizou-se a lousa branca para listar as atividades que deveriam ser executadas, estimando-se os tempos necessários para cada tarefa. O resultado desta análise pode ser observado na figura 6, configurando-se assim como o planejamento da iteração.

Figura 6: Análise de atividades x tempo

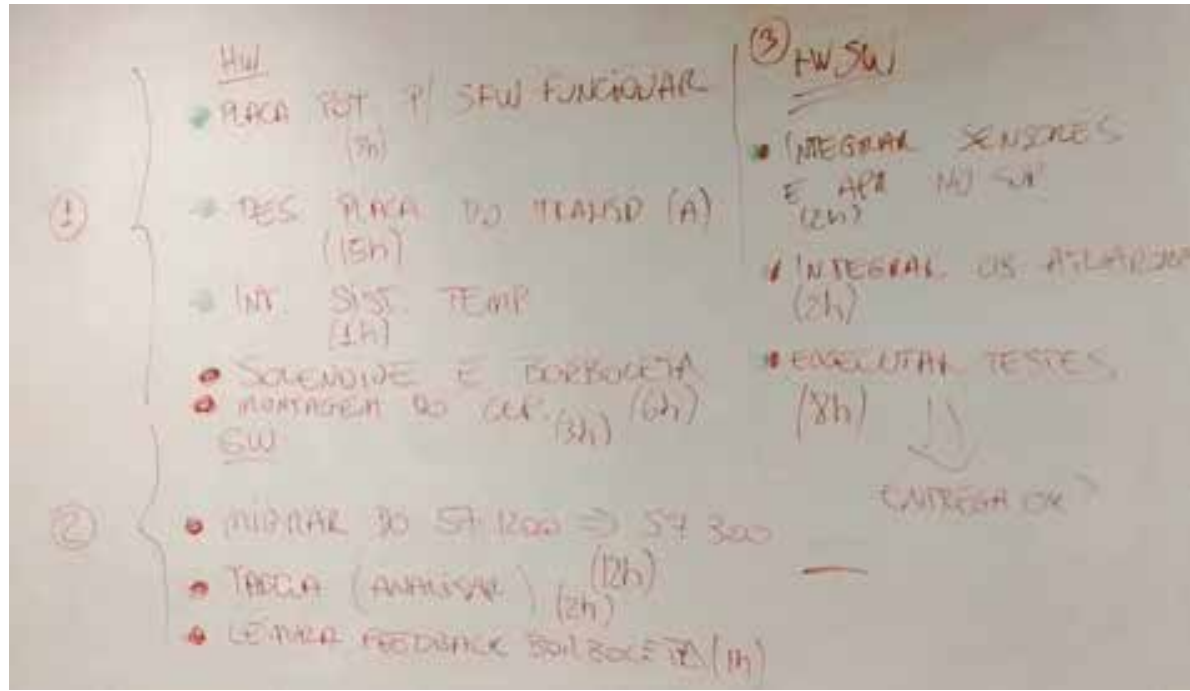

Fonte: Dos autores (2014) 
Finalizada a reunião $\mathrm{R} 2$, deu-se início à fase de Ação, em que os pesquisadores buscaram seguir o planejamento e, o líder, o plano de comunicação. Algumas vezes, em virtude de outras atividades, o líder não conseguiu fazer o Feed todos os dias com ambos os pesquisadores.

Já finalizada a fase de Ação, realizou-se a reunião $\mathrm{R} 3$, que iniciou com a seguinte pergunta para o time: "Você acredita que com mais uma fase vamos concluir a entrega?”. Neste momento, cada membro da equipe do projeto (incluindo o líder), ponderando sobre as dificuldades enfrentadas e perspectivas futuras, respondeu de forma negativa (não), configurando um consenso do time que não seria possível entregar ao final da próxima fase, sendo que o principal problema estava relacionando à super alocação da equipe em outras atividades não planejadas e não relacionadas ao projeto.

Visto as respostas negativas, o foco da reunião mudou para as ações de superação (replanejamento), buscando alternativas para a super alocação do time. O contexto era: "O que devemos fazer para entregar no prazo?”. Após algumas discussões com o time e negociações com o gerente do Instituto e outros líderes de projetos, as seguintes ações foram tomadas:

- Com impacto nas atividades de software: alocação em tempo integral do pesquisador responsável pelas atividades de software, liberando-o de todas as demais atividades não relacionadas ao projeto, além da alocação de mais uma pessoa (estagiário), focado neste desenvolvimento. Como medida adicional, o líder do projeto, que inicialmente não possuía atividades de execução, assumiu parte de algumas atividades como forma de garantir a entrega.
- Sobre as atividades de hardware: por motivo de viagem a um treinamento (inicialmente não programado, mas muito importante), haveria apenas oito horas de trabalho disponíveis do segundo pesquisador para finalização de suas atividades, sendo que este tempo não era suficiente. Como resolução, foi alterada a logística de deslocamento do pesquisador, por uma configuração mais cara, porém mais rápida, somada à utilização de horas extras, fazendo-o ter disponível para o projeto 16 horas de desenvolvimento.

POR fiM, CONCLUIU-SE QUE

TAIS MEDIDAS - TODAS RE-

LACIONADAS A AUMENTO DE

CUSTO - SERIAM SU FICIENTES

PARA SE CUMPRIR O PRAZO DA

ENTREGA, SEM NECESSIDADE DE

REDUÇÃO DE REQUISITOS.

A fase de Superação foi executada seguindo-se as atividades do planejamento e conforme as medidas de contingência citadas acima. Os resultados de tais medidas e do empenho do time foram verificados na reunião $\mathrm{R} 4$, em que a entrega foi feita em sua plenitude e dentro do prazo inicial, ou seja, ao final da fase de Superação, ganhando-se o Pulmão. Uma vez feita a entrega, o líder do projeto optou por cancelar a quarta fase (Pulmão\$), dando início antecipadamente à próxima iteração.

Como forma de ilustrar melhor a entrega, pode-se observar na figura 7 como o controlador desenvolvido nesta iteração se integra a todo o sistema. 


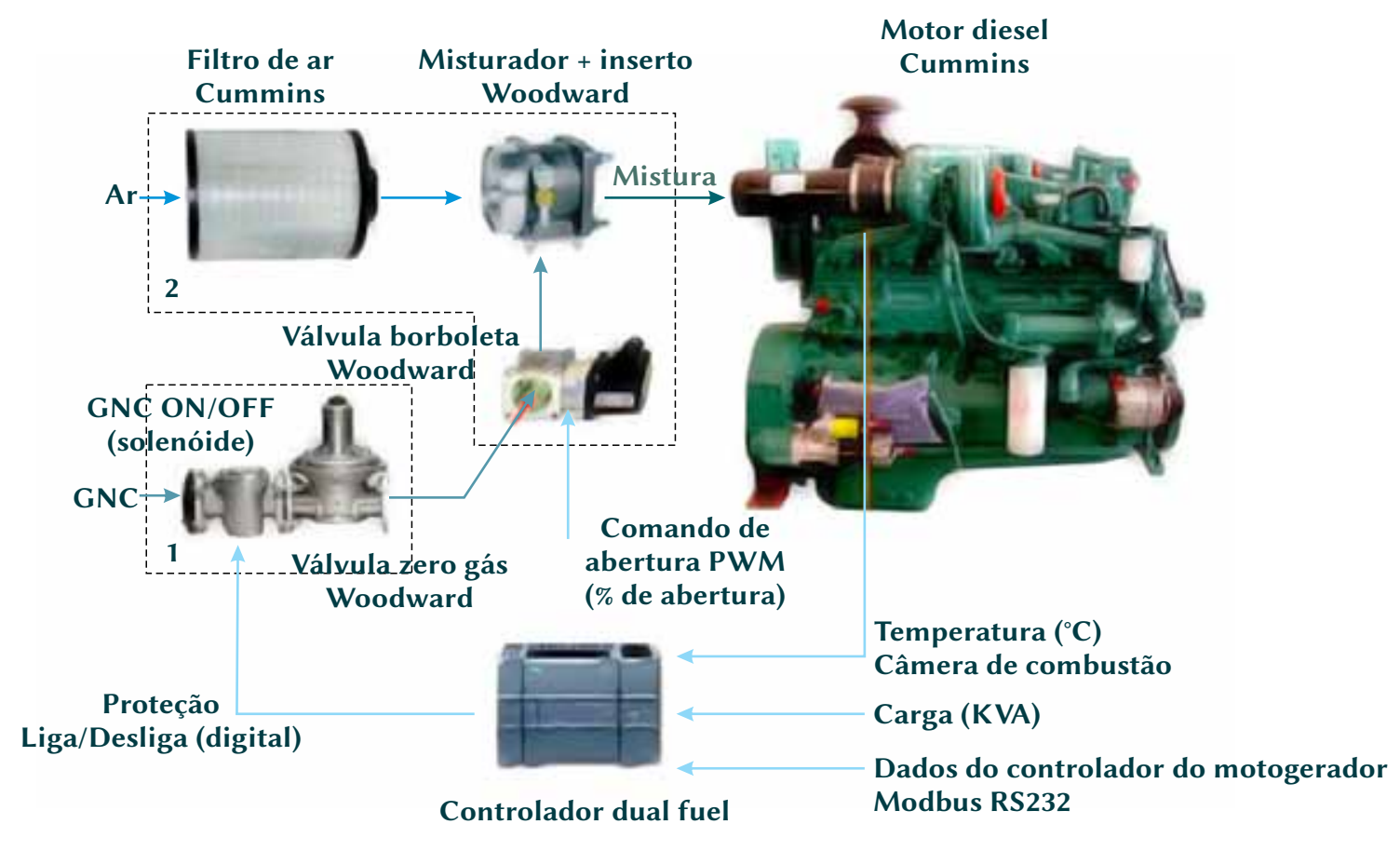

Fonte: Dos autores (2014)

b) VANTAGENS E LIMITAÇÕES

Abrindo as discussões sobre o método, as vantagens elimitações apontadas nesta seção, refletem a opinião do líder de projeto e membros das equipes de desenvolvimento, que participaram do caso piloto de aplicação do Rush.

\section{- Vantagens:}

- Implantação: o método se mostrou bastante simples e rápido ${ }^{21}$ de implantar, mesmo em equipes com profissionais com pouca experiência em gerenciamento de projeto. $\mathrm{O}$ caso de aplicação mostrou que já na primeira iteração utilizando o método, os conceitos foram bem assimilados e os resultados foram positivos.

- Feeds: as reuniões de Feed aumentaram o conhecimento do líder em relação aos diferentes aspectos do projeto, pois abordaram questões que muitas vezes não eram comentadas nas reuniões em grupo, como nos daily meetings, por exemplo.

- Planejamento: em virtude do período bastante construtivo da fase de Caos, o planejamento mostrou-se mais simples, objetivo e assertivo, ou seja, com maior qualidade. A flexibilidade e agilidade também mostraram-se outro ponto forte, uma vez que se abre uma nova “janela" de planejamento ao final da fase de Ação (reunião R3), quando isso é necessário.

- Foco e resultado: o método deixa claro o foco da iteração - entregar no prazo - fazendo com que toda a equipe fique melhor alinhada com este objetivo e consiga, com maior frequência, atingir os resultados esperados.

\footnotetext{
${ }^{21}$ Foram utilizadas aproximadamente duas horas para explicar o método à equipe e prepará-la para a iteração.
} 
- Versatilidade: o método - a exemplo de uma ferramenta - não precisa ser utilizado em todas as iterações do projeto, mais sim naquelas com entregas críticas, que envolvem alta complexidade, inovação e prazos curtos.

- Simplicidade: quase não existe burocracia e nem a necessidade de utilização de software e ferramentas específicas, pois o Rush é baseado em cultura, conceitos e boas práticas. A parte de controle e documentação cabe ao método mais abrangente de gerenciamento de projeto, onde o Rush será aplicado.

\section{- Limitações:}

- Tamanho da equipe: como todo método ágil, o Rush não é recomendado para trabalhos com grandes equipes, pois nestes casos, questões simples como fazer as reuniões de Feeds se tornariam muito trabalhosas e em alguns casos até impossíveis. No outro extremo, em projetos individuais, na fase de caos (e planejamento), acaba-se perdendo características importantes do método, como as discussões e a diversidade de ideias, técnicas, testes e soluções, que levam a um bom planejamento e, consequentemente, ao atingimento das metas.

- Aplicabilidade: o método, por ser muito focado em prazo, acaba ficando restrito a projetos que têm este quesito entre suas principais metas, perdendo assim uma aplicabilidade mais ampla e irrestrita. Também, necessita-se que o projeto seja executado em iteração, fechando mais um pouco sua aplicação.

- Relaxamento: ao se trazer o pulmão para dentro daiteração, deixando-o mais perto da atividade em execução, existe uma tendência natural da equipe relaxar, pois acaba contando com este tempo extra. Este efeito de relaxamento tende a diminuir com a ação mais presente do líder e com o amadurecimento da equipe de projeto sobre o método.

\section{CONCLUSÃO}

Como principal meta deste trabalho, tem-se o desenvolvimento de um método ágil de gerenciamento de projetos, objetivo e simples na condução de iterações, aplicável em projetos de inovação e que potencialize as entregas dentro do prazo.

Nesse contexto, uma extensa pesquisa literária foi realizada, aprofundando-se no estudo dos métodos mais relevantes para a proposta deste trabalho e identificando-se as principais práticas que serviram de base para a elaboração do novo método.
Todo esse processo foi bastante rico, principalmente as trocas de informações com experientes especialistas da área, gerentes e líderes de projeto, culminando com uma proposição sólida e concisa de método, que foi aplicado em um caso real de projeto de inovação de produto.

A análise dos resultados mostra que o método foi aplicado - e implantado - de maneira bastante simples e objetiva junto à equipe de trabalho, obtendo os resultados esperados, ou seja, a entrega foi feita dentro do prazo (cumprindo-se o cronograma estabelecido) e de forma plena 
(em linha com os requisitos de projeto). Dessa forma, conclui-se que o objetivo do trabalho foi atingido, colaborando significativamente com a redução do atraso nos cronogramas dos projetos.

Em uma visão geral, o método Rush apresentou diversos benefícios em relação aos métodos tradicionais de mercado (clássicos ou ágeis), quando aplicados isoladamente, pois mostrou potencial para ser um acelerador (ou "turbo") dos demais métodos, quando combinados com harmonia.

\section{RUSH METHOD: AGILE MANAGEMENT OF ITERATIONS FOR INNOVATION PROJECTS}

Encased in the context of management of innovation projects and of its most striking feature - be unprecedented - and supported by the huge literature about agile management and its approach strongly marked by work with iterations, this paper proposes a new agile method of conducting iterations, entitled Rush, which aims to minimize late submissions, ie to reduce the backlog of projects, particularly those with high degree of innovation. To fulfil this objective, the method addresses issues such as: chaos before planning; creativity andovershoot; individual communications; reduction of requirements and increased cost to meet deadlines; focuses on the delivery rather than the scope; besides the use of micro lungs within iterations. The method is intended to assist the leader and his team during the execution of iterations, giving rhythm and fluidity to the design, mixing techniques, good practices and behavioural, so that it could - and should - be incorporated within iterations of other known and broader methods of projects management and supported by a culture of projects management already consolidated in the company where it will be applied.

KEYWORDS: Rush. Iteration.

Innovation. Agile management.

Deadline. 


\section{REFERÊNCIAS}

Agile Manifesto. Manifesto para Desenvolvimento Ágil de Software, 2001. Disponível em: <http:// agilemanifesto.org/iso/ptbr/>. Acesso em: $14 \mathrm{abr}$. 2014.

AMARAL, D. C. et al. Gerenciamento ágil de projetos: aplicação em produtos inovadores. São Paulo: Saraiva, 2011.

BECK, K.; ANDRES, C. Extreme Programming Explained: Embrace Change. Segunda Edição. Addison-Wesley Professional, 2004.

FIGUEIREDO, Alexandre Magno. FDD em uma casca de banana: Um guia de rápido aprendizado para a Feature-Driven Development. aXmagno, março de 2007.

GOLDRATT, Eliyahu M.; COX, Jeff. A Meta: Um Processo de Melhoria Contínua. São Paulo, SP: Editora Nobel, 2003.

\section{HIGHSMITH, J. Agile Project Management:} Creating Innovative Products. Boston: AddisonWesley, 2009.

HUANG, P. M.; DARRIN, A. G.; KNUTH, A. A. Agile hardware and software system engineering for innovation. Aerospace Conference, IEEE, 2012.

KNIBERG, Henrik. Scrum e XP direto das Trincheiras: Como nós fazemos Scrum. InfoQ: 2007. Disponível em: <http://www.infoq.com/br/ minibooks/scrum-xp-from-the-trenches $>$. Acesso em: 04 abr. 2014.
MICHAELIS. Dicionário Inglês - Português. Editora Melhoramentos Ltda., 2009. Disponível em: <http:// michaelis.uol.com.br/moderno/ingles/index.php>. Acesso em: 04 set. 2014.

PALMER, Stephen R.; FELSING, John M. A Practical Guide to Feature-Driven Development. Prentice Hall, 2002.

PMI, Project Management Institute. A guide to the Project Management of Body of Knowledge (PMBOK). 5. ed. Pennsilvanya: Project Management Institute, 2013.

Estudo de Benchmarking em Gerenciamento de Projetos Brasil 2010, Project Management Institute, 2011.

PMSURVEY.ORG 2013. Edition. Project

Management Institute. Disponível em: <http://www. pmsurvey.org>. Acesso em: 17 ago. 2014.

SCHWABER, K. Agile Project Management with Scrum. Microsoft Press, Washington, 2004.

THE STANDISH GROUP. Chaos Manifesto 2013: Think Big, Act Small. The Standish Group International Inc., Boston, 2013.

Data de recebimento: $31 / 07 / 14$

Data de aprovação: 20/11/14 


\section{SOBRE OS AUTORES}

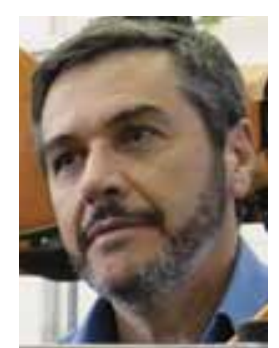

\section{Luís Gonzaga Trabasso}

É doutor em Mechanical Engineering-Loughborough University, England (1991), mestre em Engenharia e Tecnologia Espaciais pelo Instituto Nacional de Pesquisas Espaciais - INPE (1985) e graduado em Engenharia Mecânica pela Universidade Estadual Paulista Júlio de Mesquita Filho - UNESP (1982). AtualmenteéProfessor AssociadodaDivisão de Engenharia Mecânica do Instituto Tecnológico de Aeronáutica - ITA. Foi fundador do Centro de Competência em Manufatura do ITA $\mathrm{CCM} / \mathrm{ITA}$ onde coordena diversos projetos em parceria com empresas, entre elas, EMBRAER, PETROBRAS e REXAM. Suas áreas de pesquisa são: Desenvolvimento Integrado de Produtos - DIP - e Mecatrônica, com ênfase em automação industrial e robótica.

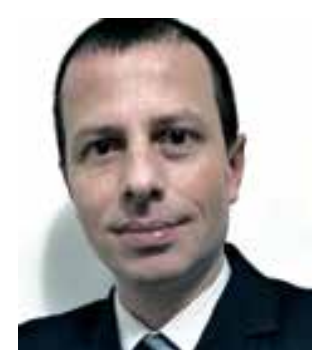

Roberto Philippi

Füllgraf

É mestre em Engenharia de Produção pelo Instituto Tecnológico de Aeronáutica (ITA), especialista em Desenvolvimento de Produtos Eletrônicos pelo Instituto Federal de Educação, Ciência eTecnologia de Santa Catarina e graduado em Engenharia Elétrica pela Universidade Federal de Santa Catarina. Atua há 17 anos nas áreas de eletrônica, automação e programação, com ênfase em pesquisa aplicada e gerenciamento de projetos de inovação. Atualmente, é Gerente do Instituto SENAI de Tecnologia em Automação e Tecnologia da Informação e Comunicação do SENAI/SC, que desenvolve projetos nas seguintes plataformas tecnológicas: Sistemas Eletrônicos e de Energia, Controle e Automação, Gestão da Produção, Engenharia de Redes e Engenharia de Software. 